\title{
Production and Secretion of Saccharomyces cerevisiae $\beta$-Glucanases: Differences between Protoplast and Periplasmic Enzymes
}

\author{
By ROSA CENAMOR, MARÍA MOLINA, JAVIER GALDONA, \\ MIGUEL SÁ NCHEZ AND CÉSAR NOMBELA* \\ Departamento de Microbiologia, Facultad de Farmacia, Universidad Complutense, \\ 28040-Madrid, Spain
}

(Received 4 August 1986; revised 3 November 1986)

\begin{abstract}
Cell-free extracts and culture medium from Saccharomyces cerevisiae S288C contained the two glucan hydrolases that are known to be periplasmically located in vegetative cells of this yeast. These were an endo-1,3- $\beta$-glucanase and a much more abundant exo-1,3- $\beta$-glucanase. Cell-free extracts of strains carrying two different mutant alleles of the $E X B I$ gene were totally deficient in the latter enzyme, whereas the former appeared in multiple heterogeneous forms, probably due to incomplete glycosylation. In contrast, protoplast lysates of wild-type and exbl mutant strains were identical in their complement of glucanases, which consisted of two enzymes clearly distinguishable from the periplasmic glucanases. One was an exo-1,3- $\beta$-glucanase, which was active on pustulan, $p$-nitrophenyl $\beta$-D-glucoside, salicin and cellobiose, and was of higher $M_{\mathrm{r}}$ than periplasmic exoglucanase. The other was a hydrolase acting on $1,3-\beta$-glucan and $1,6-\beta$ glucan but not the simple glucosides, which was not retained by DEAE-Biogel. Wild-type and exbl mutant protoplasts secreted portions of the glucanases detected in protoplast lysates, when cultured in osmotically stabilized regeneration medium; the former also secreted the periplasmic exo-1,3- $\beta$-glucanase but the latter consistently failed to secrete it. It is concluded that the classically known glucanases of $S$. cerevisiae, located in the periplasmic space, must be formed as active enzymes, upon secretion, from inactive cytoplasmic precursors. On the other hand, the two new protoplast glucanases could be secreted by an alternative route that assures their incorporation into the wall structure, thus making their release into the culture medium more difficult.
\end{abstract}

\section{INTRODUCTION}

Saccharomyces cerevisiae glucanases are thought to be autolysins since 1,3- $\beta$-glucan with occasional 1,6- $\beta$-linkages is the most abundant component in the cell wall of this yeast. Moreover, the production of glucanases in this species is growth associated (del Rey et al., $1979 a$; Larriba et al., 1984) and takes place at a certain phase of the cell cycle (del Rey et al., $1979 b$ ), suggesting that their activity may be necessary at some stages during morphogenesis.

For a number of years the complement of glucan-hydrolysing enzymes in vegetative $S$. cerevisiae seemed to be well characterized and simple. Workers were able to detect, in cell-free extracts, an exo-1,3- $\beta$-glucanase that released glucose residues from chain ends, and an endo-1,3$\beta$-glucanase which attacked internal bonds (Farkas et al., 1973). The cooperation of both enzymes could be envisaged as leading to the controlled dissolution of glucan, thus causing cell wall modification. It is also well established that exo-1,3- $\beta$-glucanase represents a very high percentage of the total glucanase activity; it is less specific than the endoglucanase because it also hydrolyses 1,6 - $\beta$-linkages and even has $\beta$-glucosidase activity since it acts on synthetic glucosides such as $p$-nitrophenyl $\beta$-D-glucoside (Farkas et al., 1973; Santos et al., 1979). In 
addition to these two enzymes, the synthesis of a third glucanase is activated upon meiosis and sporulation (del Rey et al., 1980).

Several observations subsequently made it difficult to maintain the simple concept of two glucanases in vegetative cells of $S$. cerevisiae and the role attributed to them. One was our report of a mutant defective in exo-1,3- $\beta$-glucanase (Exb- phenotype) that has no other phenotypic alterations: it grows, mates and sporulates normally (Santos et al., 1979, 1982). It can be concluded either that the functions of exo-1,3- $\beta$-glucanase (which include the hydrolysis of 1,6- $\beta$ linkages) are dispensable or that they are exerted by some other enzyme. In fact Sánchez et al. (1982) described a second exoglucanase, which is produced in much smaller amounts but is serologically related to the major exoglucanase. A further complication arises from the report of Hien \& Fleet (1983) that purportedly extends the number of glucanases in vegetative $S$. cerevisiae to six different enzymes, some of which are present in a very reduced proportion. This number of glucan-hydrolysing enzymes seems too high; some of them may perhaps be products of proteolytic modification or intermediate glycosylation forms.

These reports warranted further characterization of exo-1,3- $\beta$-glucanase-deficient mutants in order to gain an understanding of the $\beta$-glucanase complement of $S$. cerevisiae. We have concentrated especially on the analysis of protoplast lysates and of the enzymes secreted by regenerating protoplasts, and have obtained evidence showing that the secretion process is crucial for the formation of the active enzyme forms that are detected in cell-free extracts and culture media.

\section{METHODS}

Strains and growth conditions. S. cerevisiae S288C (MAT $)$ was obtained from the Yeast Genetics Stock Center (California, USA). Several Exb- mutants, defective in exo-1,3- $\beta$-glucanase production (Santos et al., 1979) and affected in the EXB1 gene, were used. S. cerevisiae C31C (MATa, exbl-1) has been described; this strain was repeatedly backcrossed with the wild-type strain S288C to obtain S. cerevisiae R22C (MATa, exb1-1). Another $\mathrm{Exb}^{-}$mutant was obtained in the course of this research by the method described by Santos et al. (1979); the mutation affected a single mendelian gene that did not complement with exbl-l and therefore was characterized as another mutant allele of the same gene and named exb1-2. After several backcrosses, $S$. cerevisiae strain J1C $(M A T \mathbf{a}, e x b 1-2)$ was obtained and used for biochemical analysis.

Liquid cultures were obtained by inoculating flasks with one-fourth of their capacity of YED medium $(2 \%, w / v$, glucose and $1 \%, \mathrm{w} / \mathrm{v}$, yeast extract) and shaking them in an orbital incubator (Gallenkamp) at $28^{\circ} \mathrm{C}$.

Enzyme preparations. Exponential-phase cultures were centrifuged and the supernatant fluids were dialysed against 10 mM-sodium succinate buffer $\mathrm{pH} 5.3$ before use in enzyme studies. Cell extracts were prepared from cultures in the same phase. The cells were washed with the above buffer, resuspended in it and disrupted for $90 \mathrm{~s}$ in a Braun homogenizer with an equal weight of $0.2 \mathrm{~mm}$ ballotini beads. The suspension was decanted, and cell walls and debris were removed by low-speed centrifugation. Extracts were centrifuged at $48000 \mathrm{~g}$ for $30 \mathrm{~min}$ and their supernatant fluids dialysed against $10 \mathrm{~mm}$-sodium succinate $\mathrm{pH} 5 \cdot 3$.

To obtain protoplasts, pelleted cells from an exponential-phase culture were resuspended at a final concentration of $10 \mathrm{mg}$ (dry weight) $\mathrm{ml}^{-1}$ in $50 \mathrm{mM}$-Tris/ $/ \mathrm{HCl}$ buffer $\mathrm{pH} 7.4$ containing $0.6 \mathrm{M}-\mathrm{KCl}, 10 \mathrm{~mm}-\mathrm{MgSO}_{4}$, $10 \mathrm{mM}$-mercaptoethanol and $40 \mu \mathrm{l}$ glusulase $\mathrm{ml}^{-1}$. After $90 \mathrm{~min}$ incubation at $24^{\circ} \mathrm{C}$ with gentle shaking almost $90 \%$ of the cells were converted into protoplasts, which were then washed two to five times with 50 mM-sodium acetate buffer $\mathrm{pH} 5 \cdot 3$, osmotically stabilized with $0.9 \mathrm{M}$-sorbitol and supplemented with $10 \mathrm{mM}-\mathrm{MgSO}_{4}$. To prepare protoplast lysates, protoplasts were centrifuged and resuspended in $10 \mathrm{mM}$-sodium succinate $\mathrm{pH} 5 \cdot 3$, disruption being completed in a Potter homogenizer. Homogenates were centrifuged at $48000 \mathrm{~g}$ for $30 \mathrm{~min}$ and the corresponding supernatant fluids dialysed against $10 \mathrm{~mm}$-sodium succinate $\mathrm{pH} 5.3$ at $4{ }^{\circ} \mathrm{C}$.

Protoplasts were also incubated at $24^{\circ} \mathrm{C}$ under regeneration conditions to obtain preparations of their secretion products. The protoplasts were washed five times, as described above, and resuspended in a stabilized medium ( $1 \%$ yeast extract, $2 \%$ glucose, $0.9 \mathrm{M}$-sorbitol and $\left.10 \mathrm{~mm}-\mathrm{MgSO}_{4}\right)$. The suspension was incubated, with gentle shaking, at $24^{\circ} \mathrm{C}$ for $5 \mathrm{~h}$, protoplasts being finally centrifuged and the supernatant fluids dialysed against sodium succinate $\mathrm{pH} 5.3$ at $4^{\circ} \mathrm{C}$.

Chromatographic procedures. The dialysed enzyme preparations were analysed by DEAE-Biogel A (Bio-Rad) ion-exchange chromatography and by Sephadex G-200 (Pharmacia) gel filtration chromatography. DEAE-Biogel chromatography was carried out in a column $(13 \times 0.95 \mathrm{~cm})$ equilibrated with $10 \mathrm{mM}$-sodium succinate $\mathrm{pH} 5 \cdot 3$. Retained proteins were eluted with a linear $\mathrm{NaCl}$ gradient $(0$ to $0.75 \mathrm{M})$ in the same buffer, $1 \mathrm{ml}$ fractions being collected. For gel filtration, dialysed enzyme preparations were concentrated, applied to a column $(58 \times 0.95 \mathrm{~cm})$ packed with Sephadex G-200 and equilibrated with 25 mM-sodium succinate pH 5.3. Elution was with the same 
buffer at a flow rate of $2 \mathrm{ml} \mathrm{h}^{-1}, 1 \mathrm{ml}$ fractions being collected. All chromatographic procedures were carried out at $4^{\circ} \mathrm{C}$.

Enzyme assays. Details of the assay procedures were as described by Santos et al. (1979), except that $6 \mathrm{~h}$ incubation was used for column fractions to detect small amounts of enzyme. Assays of 1,3- $\beta$-glucanase and 1,6- $\beta$ glucanase were based on the release of reducing sugar from laminarin and pustulan respectively. Exo-1,3- $\beta$ glucanases are usually active on $p$-nitrophenyl $\beta$-D-glucoside (pNPG), whose hydrolysis was followed by the release of $p$-nitrophenol. Endo-1,3- $\beta$-glucanase was characterized by its action on periodate-oxidized laminarin. One enzyme unit was defined as the amount of enzyme which released $1 \mathrm{nmol}$ of the reaction product (glucose or equivalent reducing power, or $p$-nitrophenol) under the conditions of the reaction.

Substrates and chemicals. Laminarin was purchased from Koch-Light, pustulan from Calbiochem, pNPG from Sigma, and glusulase from Dupont. Periodate-oxidized laminarin was prepared by the procedure of Hay et al. (1965).

\section{RESULTS}

\section{Alterations in glucanase production determined by exbl mutations}

To re-examine the implications of our findings about $\mathrm{Exb}^{-}$mutants on the role of glucanase in $S$. cerevisiae, we characterized further several exbl-1 strains and isolated new $\mathrm{Exb}^{-}$mutants. The procedure previously used (Santos et al., 1979) was applied again and a new Exb- mutant was isolated (see Methods) which carried another mutant allele, namely exb1-2, of the same gene. No other types of mutant have been isolated, suggesting that $E X B I$ is the only gene controlling exo$1,3-\beta$-glucanase function that can be defined by this method.

Since only cell-free extracts and culture fluids, of mutant and wild-type, had been compared for their glucanase content (Santos et al., 1979) we also examined protoplast lysates and the enzymes secreted by protoplasts when cultured in regeneration medium. Confirming previously published evidence, the activity of cell-free extracts and culture fluids from exbl-1 strains was much reduced on laminarin, negligible on $\mathrm{pNPG}$ and undetectable on pustulan, as compared to the wild-type (Table 1). This was consistent with the lack of production of the major exo-1,3- $\beta$ glucanase by those cells (see below). Unexpectedly, however, activities against the three substrates were essentially the same in wild-type and mutant protoplast lysates (Table 1), showing that the mutation did not affect the complement of glucan-hydrolysing enzymes inside the cytoplasmic membrane. It was also clear that secretion of a significant proportion of laminarinase activity was impaired in the mutants as compared to the wild-type but, even so, significant levels of pNPG and pustulan hydrolases were clearly detectable among their secretion products (Table 1).

Table 1. Glucan-hydrolysing activities in different preparations from S. cerevisiae $S 288 C$ (wild-type) and exb1 mutant strains $C 31 C$ and $R 22 C$

Data correspond to total units in $2 \times 10^{10}$ cells or protoplasts or in the culture medium where the same amount of cells or protoplasts was grown to exponential phase or incubated under regeneration conditions, respectively. Values in parenthesis indicate specific activity (units $\mathrm{mg}$ protein ${ }^{-1}$ ).

Enzyme activity in:

\begin{tabular}{|c|c|c|c|c|c|}
\hline Substrate & Strain & $\begin{array}{l}\text { Cell-free } \\
\text { extract }\end{array}$ & $\begin{array}{c}\text { Protoplast } \\
\text { lysate }\end{array}$ & $\begin{array}{l}\text { Culture } \\
\text { medium }\end{array}$ & $\begin{array}{l}\text { Protoplast } \\
\text { secretion } \\
\text { products }\end{array}$ \\
\hline Laminarin & $\begin{array}{l}\text { S288C } \\
\text { C } 31 \mathrm{C} \\
\text { R22C }\end{array}$ & $\begin{array}{r}417 \cdot 4(4 \cdot 1) \\
50 \cdot 4(1 \cdot 4) \\
36 \cdot 7(0 \cdot 6)\end{array}$ & $\begin{array}{l}110.6(1.5) \\
118.2(1.6) \\
105.3(1.9)\end{array}$ & $\begin{array}{r}1057.2(6.9) \\
187.2(1.2) \\
156.5(0.8)\end{array}$ & $\begin{array}{rr}1128.0 & (13.4) \\
332.0 & (1.8) \\
351.0 & (5.0)\end{array}$ \\
\hline pNPG & $\begin{array}{l}\text { S288C } \\
\text { C } 31 \mathrm{C} \\
\mathrm{R} 22 \mathrm{C}\end{array}$ & $\begin{array}{r}251 \cdot 7(2 \cdot 4) \\
5 \cdot 3(0 \cdot 1) \\
3.7(0 \cdot 1)\end{array}$ & $\begin{array}{l}90.6(1.2) \\
73.4(1.0) \\
74.3(1.4)\end{array}$ & $\begin{array}{r}630.0(4.1) \\
0.0(0.0) \\
0.0(0.0)\end{array}$ & $\begin{array}{ll}459.6 & (5 \cdot 4) \\
128.0 & (0 \cdot 7) \\
121.3 & (1.7)\end{array}$ \\
\hline Pustulan & $\begin{array}{l}\text { S288C } \\
\text { C } 31 \mathrm{C} \\
\text { R22C }\end{array}$ & $\begin{array}{r}34.5(0.3) \\
0.0(0.0) \\
0.0(0.0)\end{array}$ & $\begin{array}{r}11.6(0.2) \\
3.4(0.1) \\
7.4(0.1)\end{array}$ & $\begin{array}{r}88.2(0.6) \\
0.0(0.0) \\
0.0(0.0)\end{array}$ & $\begin{array}{rr}324.0 & (3.8) \\
37.5 & (0.3) \\
90.8 & (1.3)\end{array}$ \\
\hline
\end{tabular}




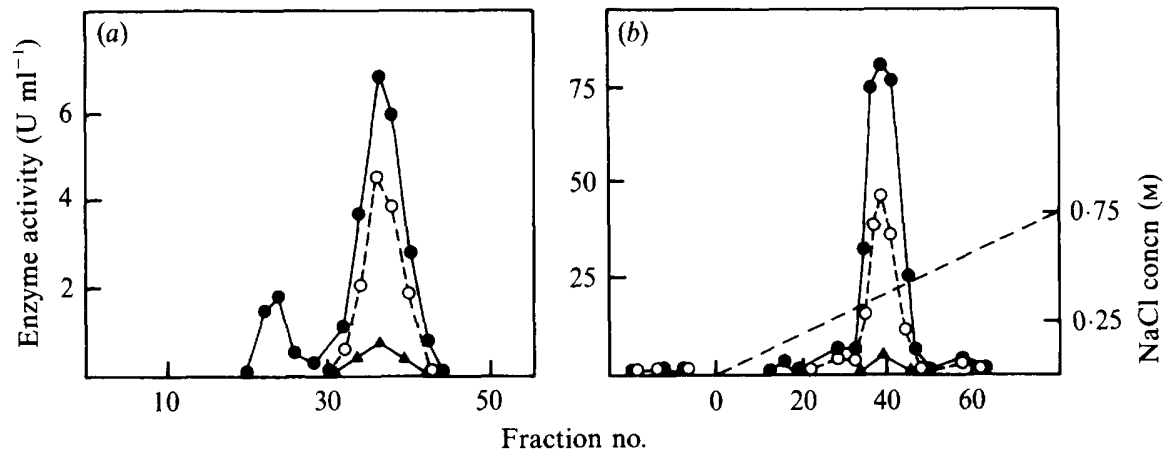

Fig. 1. Analysis by Sephadex G-200 gel filtration (a) and by DEAE-Biogel ion-exchange chromatography $(b)$ of $\beta$-glucanases present in cell-free extracts of $S$. cerevisiae $\mathrm{S} 288 \mathrm{C}$ (wild-type). The amounts of total protein applied to the columns were $4 \mathrm{mg}(a)$ and $52 \mathrm{mg}(b)$. Activity against laminarin

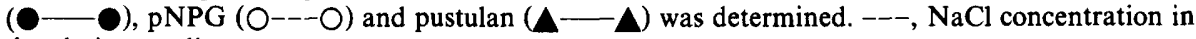
the elution gradient.

Sephadex G-200 gel filtration (Fig. $1 a$ ) of extracts from the wild-type strain S288C led to the separation of two peaks of laminarinase activity, which corresponded to the endo-1,3- $\beta$ glucanase (the larger enzyme), and the exo-1,3- $\beta$-glucanase, the smaller but more abundant form which was also active on pustulan and pNPG. These two enzymes eluted together, in a peak around fraction 40 , when the same preparations were analysed by DEAE-Biogel chromatography (Fig. $1 b$ ), although they could be resolved by further chromatography on hydroxyapatite (data not shown). However, the ion-exchange chromatography revealed tiny amounts of glucanase activity eluting before and after the major peak. This observation is in agreement with those of Hien \& Fleet (1983) but it is not clear whether the minor peaks correspond to different enzymes or to degradation products of the well-characterized glucanases. Cell-free extracts from strains C31C (exb1-1), R22C (exbl-1) and J1C (exbl-2) were processed in the same manner (Fig. 2). The results clearly showed that the laminarinase peak active on pNPG and pustulan, and with the chromatographic properties of the exo-1,3- $\beta$-glucanase, was totally absent from the three preparations. However, the lack of exo-1,3- $\beta$-glucanase did not seem to be the only biochemical alteration in these mutant strains; the remaining glucanase activity appeared very heterogeneous by both types of column chromatographic analysis (Fig. $2 a, b, e, f$ ) and split into two peaks in the case of strain R22C (Fig. 2c, d). In this last case, relevant fractions of both peaks were active when analysed against periodate-oxidized laminarin, demonstrating an endohydrolytic mode of action. The endo- $\beta$-glucanase appeared to be more unstable in the $e x b l$ mutants, but some heterogeneity was apparent, probably due to partial proteolysis (M. Sánchez \& C. Nombela, unpublished).

The lack of exo-1,3- $\beta$-glucanase in culture fluids of the three mutants was also established. Analysis of this type of preparation from strain R22C (Fig. $3 c, d$ ) showed only endo-1,3- $\beta$ glucanase eluting in two wide peaks by both chromatographic procedures. The endohydrolytic mode of action was confirmed by testing relevant fractions. By contrast, culture fluids from the wild-type S288C gave very similar results (Fig. $3 a, b$ ) to those of cell-free extracts when analysed by both procedures.

\section{Molecular forms of glucanases present in and secreted by protoplasts of Exb- mutants and the wild-type}

A clear and somewhat unexpected conclusion emerged from the evidence shown above. Whereas mutations in the $E X B 1$ gene clearly affected the glucanase activity and glucan hydrolases present in cell-free extracts and culture fluids (and therefore glucanases produced and secreted by the cells), the activities in protoplast lysates were unaltered by the same genetic defect. This could'indicate that the molecular forms of these enzymes inside the cytoplasmic 

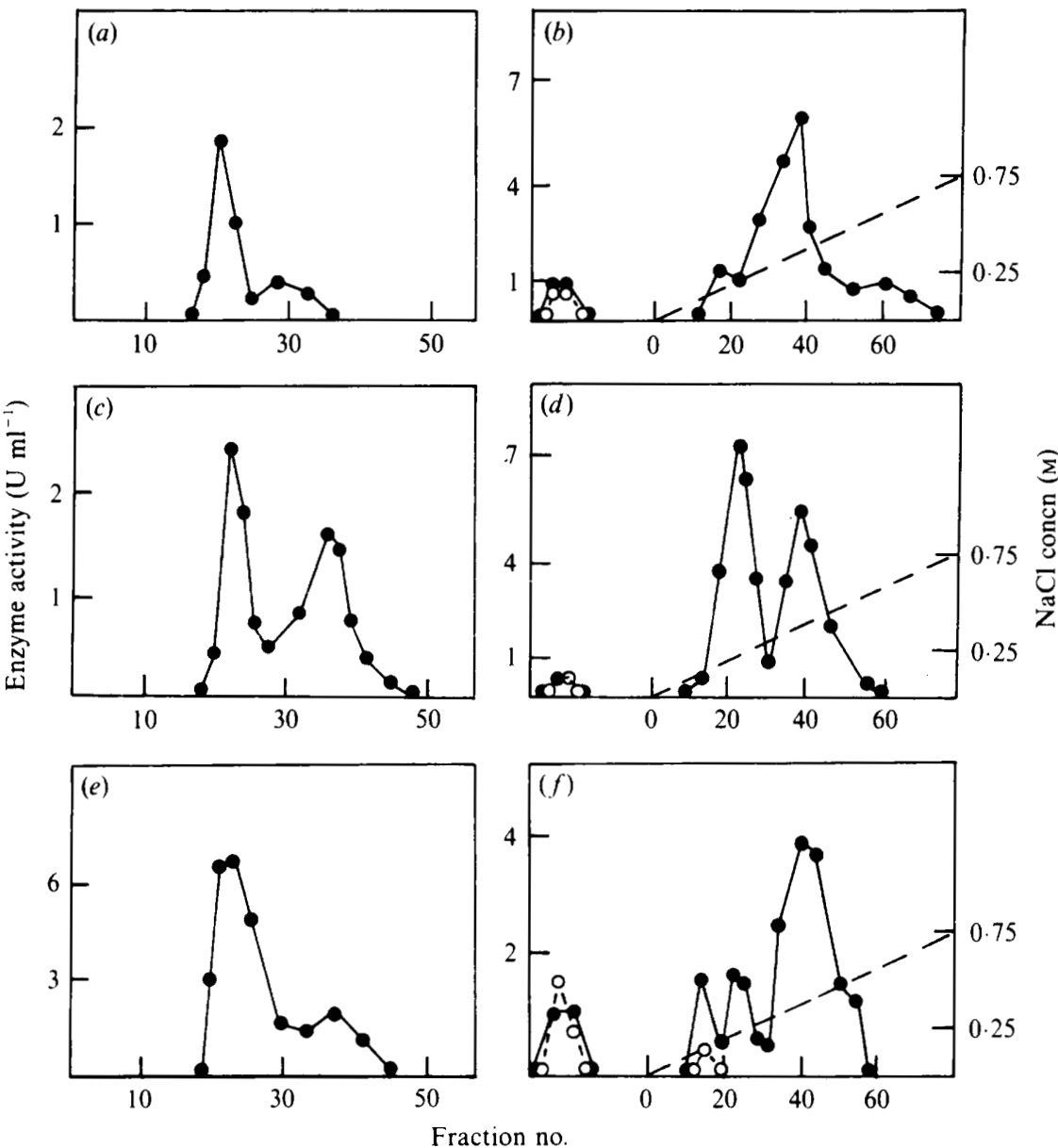

Fig. 2. Analysis by Sephadex G-200 gel filtration $(a, c, e)$ and by DEAE-Biogel ion-exchange chromatography $(b, d, f)$ of $\beta$-glucanases present in cell-free extracts obtained from the $S$. cerevisiae exbl mutant strains C31C $(a, b), \operatorname{R} 22 \mathrm{C}(c, d)$ and $\operatorname{J1C}(e, f)$. The amounts of total protein applied to the columns were $10 \mathrm{mg}(a), 78 \mathrm{mg}(b), 22 \mathrm{mg}(c), 113 \mathrm{mg}(d), 21 \mathrm{mg}(e)$ and $62 \mathrm{mg}(f)$. Symbols as in Fig. 1.

membrane were quite different from the active glucanases exported outside it, and were identical in wild-type and exbl mutant strains. The results of Fig. 4 demonstrated that this contention was correct. Gel filtration and ion-exchange chromatography of protoplast lysates from $S$. cerevisiae strains S288C (EXBI) (Fig. 4a, b) and R22C (exbl-I) (Fig. 4c, d) gave essentially identical patterns of glucanases, which were very different from those of cell-free extracts from either strain. Two peaks of laminarinase were observed by both chromatographic procedures. The larger one coincided with a peak of pNPG-hydrolysing activity and it also acted on pustulan in a limited manner. It could be characterized as an exo-1,3- $\beta$-glucanase according to currently used criteria, but chromatographically this enzyme was completely different from the exo-1,3- $\beta$-glucanase of cell-free extracts, in which the exbl mutants were deficient. The protoplast enzyme eluted around fraction 28 from the Sephadex G-200 column, and around fraction 30 from the DEAE-Biogel column, whereas the typical exoglucanase from extracts eluted around fractions 38 and 40 respectively. It was of interest that peak fractions of the exoglucanase in protoplast lysates also hydrolysed glucosides such as salicin and cellobiose, which could be due either to a broader specificity of the glucanase or to co-elution of a $\beta$ glucosidase. The other peak of laminarinase in protoplast lysates represented a new form totally 


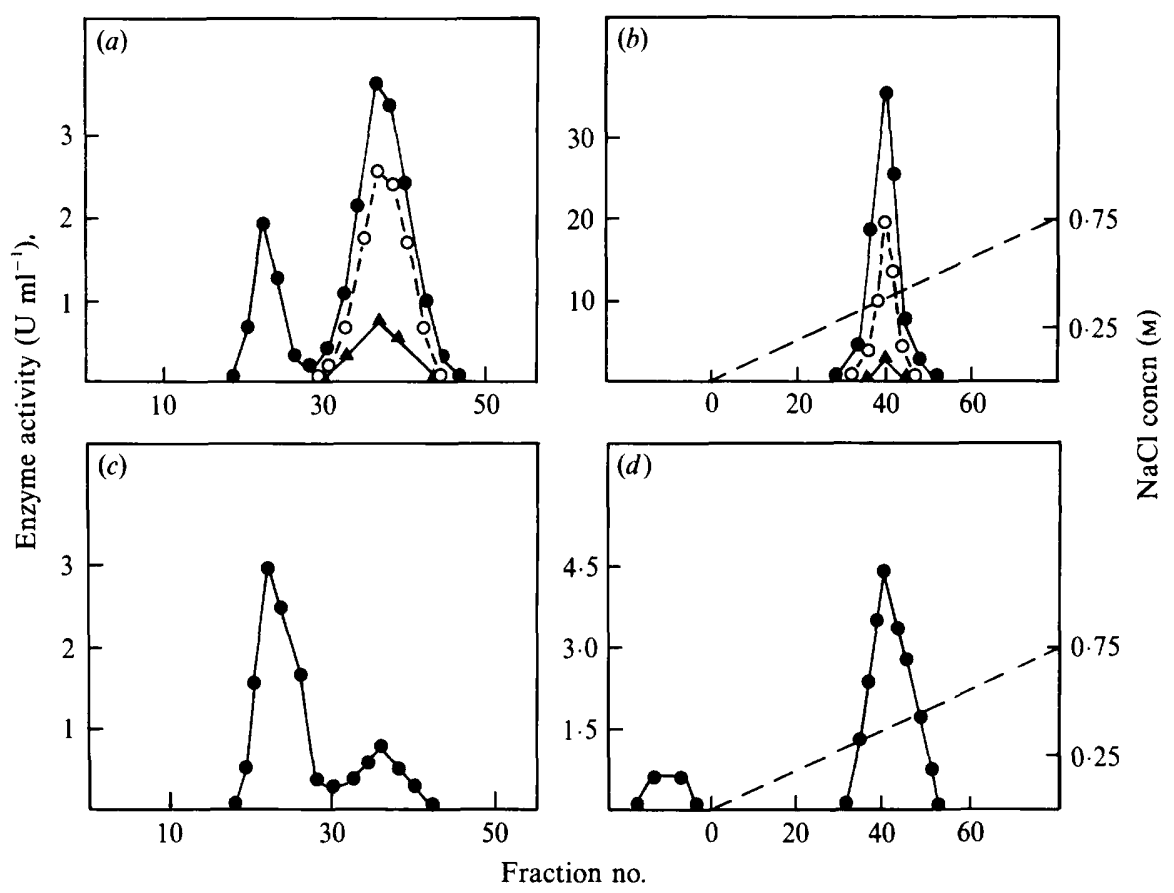

Fig. 3. Analysis by Sephadex G-200 gel filtration $(a, c)$ and by DEAE-Biogel ion-exchange chromatography $(b, d)$ of $\beta$-glucanases present in culture medium of $S$. cerevisiae $\operatorname{S288C}$ (wild-type) $(a, b)$ and $S$. cerevisiae R22C (exb1-1) (c,d). The amounts of total protein applied to the columns were $3.6 \mathrm{mg}$ $(a), 28 \mathrm{mg}(b), 3.6 \mathrm{mg}(c)$ and $25 \mathrm{mg}(d)$. Symbols as in Fig. 1.

different from those detected in the other preparations; this enzyme acted on laminarin and pustulan, but not on pNPG, and it was not retained by DEAE-Biogel.

These results suggested that protoplasts of wild-type and exbl mutant strains might differ in their capacity to secrete the exo-1,3- $\beta$-glucanase with the properties of that found in cell-free extracts and culture medium. The results in Fig. 5 confirmed that this was the case. A very clear peak corresponding to the major exo-1,3- $\beta$-glucanase active on the three substrates appeared when secretion products of the wild-type protoplasts (Fig. $5 a$ ) were chromatographed, but it was completely absent in the same preparations from the mutant protoplasts (Fig. $5 b$ ). Interestingly, portions of the protoplast enzymes, namely the exoglucanase (eluting around fraction 28 from DEAE-Biogel) and the laminarinase-pustulanase (which was not retained by the ionexchanger), present in protoplast lysates seemed to be secreted by the protoplasts under these conditions (Fig. 5a,b). The same conclusions could be obtained from analysis of these preparations by Sephadex G-200 gel filtration as well as from studies of the other mutant strains $\mathrm{C} 31 \mathrm{C}(e x b 1-1)$ and $\mathrm{JlC}(e x b 1-2)$.

\section{DISCUSSION}

Two fundamental and related issues seem to be most relevant for research on yeast glucanases. One is the role that these enzymes could play in the controlled dissolution of glucan, the cell wall structural component, during different stages of morphogenesis. The other is the secretion of these proteins through the membrane, which results in the release to the periplasmic space of enzymes that are active against cell wall components; in this regard glucanases could represent an interesting model system to study yeast protein secretion, as several other yeast enzymes have done (Schekman, 1985).

We believe that the evidence presented in this paper contributes to the clarification of both these aspects and opens the way for new approaches. In an effort to reconcile observations from 

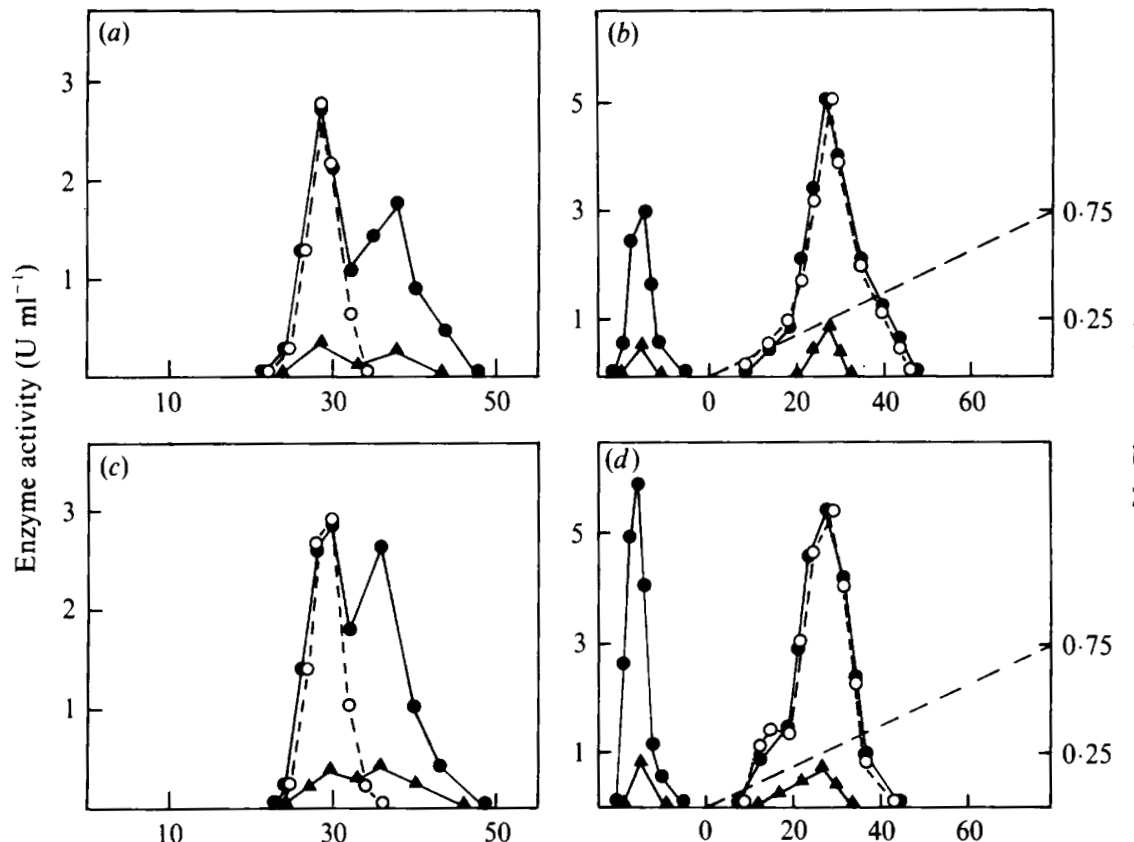

Fraction no.

Fig. 4. Analysis by Sephadex G-200 gel filtration $(a, c)$ and by DEAE-Biogel ion-exchange chromatography $(b, d)$ of $\beta$-glucanases present in protoplast lysates from $S$. cerevisiae $\mathrm{S} 288 \mathrm{C}$ (wild-type) $(a, b)$ and $\mathrm{R} 22 \mathrm{C}(e x b l-1)(c, d)$. The amounts of total protein applied to the columns were $6 \mathrm{mg}(a), 18 \mathrm{mg}$ $(b), 8 \mathrm{mg}(c)$ and $29 \mathrm{mg}(d)$. Symbols as in Fig. 1.

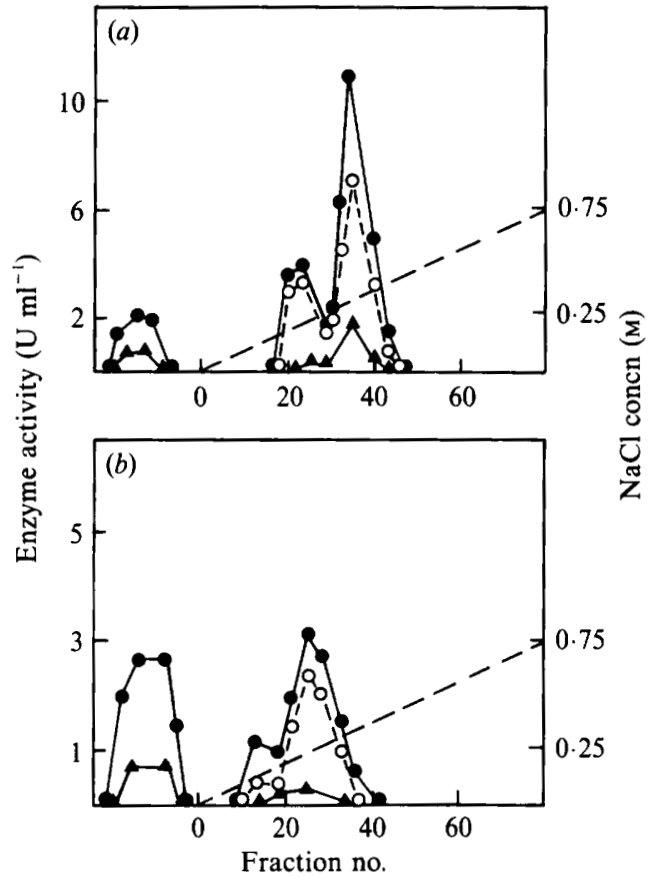

Fig. 5. Analysis by DEAE-Biogel ion-exchange chromatography of $\beta$-glucanases secreted by protoplasts from $S$. cerevisiae S288C (wild-type) (a) and R22C (exbl-1) (b) when cultured in regeneration medium. The amounts of total protein applied to the columns were $7 \mathrm{mg}(a)$ and $12 \mathrm{mg}(b)$. 
various laboratories we used sodium succinate, the buffer employed by Hien \& Fleet (1983), for our column chromatographies, instead of the acetate buffer of many of our previous studies. The re-examination of $\mathrm{Exb}^{-}$mutants, affected in the $E X B I$ gene, reinforced the conclusion about the dispensability of vegetative exo-1,3- $\beta$-glucanase (Santos et al., 1982), the most abundant glucan hydrolase produced by $S$. cerevisiae cells. Mutants carrying exb1 alleles failed to produce this enzyme and their protoplasts failed to secrete it; however, no alterations in their morphogenesis were observed. It can always be argued that tiny, undetectable amounts of exo-1,3- $\beta$-glucanase, sufficient to accomplish its biological role, could still be produced due to leakiness of the mutation. This seems unlikely because exo-1,3- $\beta$-glucanase represents a high percentage (much higher than $50 \%$ ) of the total glucanase activity in vegetative cells, and it is difficult to imagine that the cells could withstand its reduction to an undetectable level without any further growth alteration if the enzyme is critical for growth and morphogenesis. Moreover, a $S$. cerevisiae DNA fragment containing the $E X B I$ gene has recently been cloned on the basis of its capacity to complement exbl mutations (Nebreda et al., 1986). These results clearly show that EXBl is the structural gene for exo-1,3- $\beta$-glucanase, and that disruption of this gene in the cells (using an integrative vector carrying internal fragments of the cloned gene) resulted in $\mathrm{Exb}^{-}$clones with no further alterations in their phenotype other than the biochemical deficiency. This procedure of gene disruption is known to alter the gene in such a way that a limited formation of the gene product does not seem feasible.

The $S$. cerevisiae exo-1,3- $\beta$-glucanase is recognized by its capacity to hydrolyse laminarin and pustulan, two types of glucan substrates that are readily available but not of identical conformation to yeast glucan, together with the synthetic glucoside pNPG. Workers tend to rely on the recognition of pNPG as characteristic of an exo-hydrolytic mode of action, but this is not necessarily true; we have shown that exo-1,3- $\beta$-glucanase of Candida albicans 1001 does not hydrolyse pNPG (Molina et al., 1987). It is possible that the exo-1,3- $\beta$-glucanase of $S$. cerevisiae is simply a $\beta$-glucosidase that happens to act on $1,3-\beta$ - and $1,6-\beta$-linkages of glucan, but is produced for metabolic and not morphogenetic purposes; however, the likelihood of this being so is reduced by the fact that exoglucanase production is growth associated (del Rey et al., $1979 a$; Larriba et al., 1984), unlike metabolic hydrolases, which are usually subject to catabolite repression. Alternatively, exo-1,3- $\beta$-glucanase could participate in glucan degradation for morphogenetic purposes, as postulated by Cortat et al. (1972), but some of the other glucan hydrolases might be able to substitute for it.

New and somewhat unexpected conclusions, relevant to the idea of alternative glucanases, can be obtained from our analysis of protoplast preparations. The glucan hydrolases in protoplast lysates were chromatographically different from those in cell-free extracts or culture fluids. The two enzymes in protoplast lysates were an exo-1,3- $\beta$-glucanase (apparently active on pustulan, pNPG, salicin and cellobiose), with an $M_{\mathrm{r}}$ higher than that of the exo-1,3- $\beta$-glucanase in cell-free extracts, and another glucanase that behaved completely differently from any of the known $S$. cerevisiae glucan hydrolases as it seemed to act on laminarin and pustulan (but not on pNPG) and was not retained by DEAE-Biogel. Moreover, these two enzymes were not only present in protoplast lysates of the wild-type strain but also in those of exb1 mutants which displayed identical glucanase patterns. It follows that active glucanases situated inside the cytoplasmic membrane (or, alternatively, those which can be activated by disrupting protoplasts) are different from those that are located in the periplasmic space and released into the culture medium. Another clear conclusion is that the formation of the protoplast glucanases is independent of $E X B 1$, the structural gene of the major, classical periplasmically located exo1,3- $\beta$-glucanase of $S$. cerevisiae. Consistent with this, wild-type protoplasts did secrete significant amounts of the major exo-1,3- $\beta$-glucanase of cell-free extracts, along with portions of the protoplast glucanases, while an enzyme with the properties of the major periplasmic exo-1,3$\beta$-glucanase was totally absent from secretion product preparations from $e x b l$ protoplasts, in which the two protoplast glucanases were detected. The possibility of these differences between glucanases in protoplast lysates and in cell-free extracts being caused by a protease present in the protoplasting enzyme complex can be excluded because thoroughly washed protoplasts continue to secrete substantial amounts of both types of glucanase forms. 
The following model of glucanase formation in $S$. cerevisiae emerges from the evidence available. The classically known exo-1,3- $\beta$-glucanase and endo-1,3- $\beta$-glucanase, located in the periplasmic space and culture medium, and undetectable in protoplast lysates, are activated as a result of a secretion process of inactive precursors through the cytoplasmic membrane. The secretion route defined by sec mutants is used for secretion of periplasmic exo-1,3- $\beta$-glucanase (Larriba et al., 1984) and, by analogy, probably of periplasmic endo-1,3- $\beta$-glucanase. On the other hand, two other glucanases, easy to differentiate by chromatographic procedures from the periplasmic and culture medium enzymes, can be found in protoplast lysates and among protoplast secretion products. We do not favour any precursor-product relationship between protoplast and periplasmic glucanases, because the formation of the former is totally independent of the $E X B 1$ gene. These enzymes could use a route of secretion, alternative to that defined by sec mutants, which assures their incorporation directly into the cell wall structure, so that no release into the culture medium occurs. Glucanases which also hydrolyse pustulan and pNPG can be obtained by autolysis or other treatments of isolated, thoroughly washed cell walls from $e x b l$ mutants (M. Sánchez \& C. Nombela, unpublished). Evidence for a secretion route, independent of that defined by sec mutants, which is used by many cell wall proteins has recently been presented by Sanz et al. (1986).

A note of caution seems pertinent in view of these results. To assay pNPG-hydrolysing activity in protoplast lysates as a means of determining the level of the major periplasmic exo1,3- $\beta$-glucanase (coded by the $E X B 1$ gene) is fallacious, since this enzyme in its active form is undetectable in protoplast lysates. The pNPG-hydrolysing enzyme which is present in protoplast lysates is a different glucanase or glycosidase whose formation is independent of the $E X B 1$ gene. Finally, we do not have a clear explanation for the reproducibly observed alterations in endo-1,3- $\beta$-glucanase patterns in periplasmic exo-1,3- $\beta$-glucanase deficient (exbl) mutants. The multiple heterogeneous forms may represent intermediate glycosylation forms and/or altered products of a deficient secretion/maturation process. It is also tempting to speculate that some kind of substrate outside the membrane could have an influence on the adequate maturation of the enzyme, as in the case of streptococcal amidase, a bacterial autolysin (Tomasz \& Westphal, 1971). By substrate modification, or some other mechanism, periplasmic exo-1,3- $\beta$ glucanase could affect the proper maturation and activation of periplasmic endo-1,3- $\beta$ glucanase.

We are very grateful to F. del Rey and his associates (Department of Microbiology, University of Salamanca, Spain) for having made available to us their results on the cloning of EXB1 gene, before publication. This investigation was supported by grant $83 / 1354$ from Comisión Asesora de Investigación Científica y Técnica. C. R. was a recipient of a fellowship from Ministerio de Educación y Ciencia (Spain) and M. M. from Fondo de Investigaciones Sanitarias de la Seguridad Social.

This paper is dedicated to Professor Severo Ochoa.

\section{REFERENCES}

Cortat, M. P., Matile, P. \& Wiemken, A. (1972) Isolation of glucanase containing vesicles from budding yeasts. Archives of Microbiology 82, 189-205.

Farkas, V., Biely, P. \& BaUer, S. (1973). Extracellular $\beta$-glucanases of the yeast Saccharomyces cerevisiae. Biochimica et biophysica acta 321, 246-255.

Hay, G. W., Lewis, B. A. \& Smith, F. (1965). Periodate oxidation of polysaccharides: general procedures. Methods in Carbohydrate Chemistry 5 , 357.

Hien, M. H. \& Fleet, G. H. (1983). Separation and characterization of six $(1 \rightarrow 3)-\beta$-glucanases from Saccharomyces cerevisiae. Journal of Bacteriology 156, 1204-1213.

Larriba, G., Villa, T. G., Nebreda, A. R., Olivero, I., Hernandez, L. M., Sanchez, A. \& Ramirez, M. (1984). Exo-glucanases in Saccharomyces cerevisiae: chemical nature, regulation, secretory pathway and cellular location. In Microbial Cell Wall Synthesis and Autolysis, pp. 239-248. Edited by C. Nombela. Amsterdam: Elsevier.

Molina, M., Cenamor, R. \& Nombela, C. (1987). Exo-1,3- $\beta$-glucanase activity in Candida albicans: effect of the yeast-to-mycelium transition. Journal of General Microbiology 133, 609-617.

Nebreda, A. R., Villa, T. G., Villanueva, J. R. \& DEL REY, F. (1986). Cloning of genes related to exo$\beta$-glucanase production in Saccharomyces cerevisiae: characterization of an exo- $\beta$-glucanase structural gene. Gene 47, 245-259.

del Rey, F. J., Garcla-Acha, I. \& Nombela, C. $(1979 a)$. The regulation of $\beta$-glucanase synthesis in fungi and yeast. Journal of General Microbiology 110, 83-89. 
Del Rey, F. J., Santos, T., Garcia-Acha, I. \& Nombela, C. $(1979 b)$. Synthesis of $1,3-\beta$-glucanases in Saccharomyces cerevisiae during the mitotic cycle, mating and sporulation. Journal of Bacteriology 139, 924-931.

Del Rey, F. J., Santos, T., Garcia-Acha, I. \& NombelA, C. (1980). Synthesis of $\beta$-glucanases during sporulation in Saccharomyces cerevisiae: formation of a new, sporulation specific 1,3- $\beta$ glucanase. Journal of Bacteriology 143, 621-627.

Sanchez, A., Villanueva, J. R. \& Villa, T. G. (1982). Saccharomyces cerevisiae secretes 2 exo- $\beta$ glucanases. FEBS Letters 138, 209-212.

Santos, T., Del Rey, F. J., Conde, J., Villanueva, J. R. \& Nombela, C. (1979). Saccharomyces cerevisiae mutant defective in exo-1,3- $\beta$-glucanase production. Journal of Bacteriology 139, 333-338.

Santos, T., DEl ReY, F. J., Villanueva, J. R. \& Nombela, C. (1982). A mutation (exbl-l) that abolishes exo-1,3- $\beta$-glucanase production does not affect cell-wall dynamics in Saccharomyces cerevisiae. FEMS Microbiology Letters 13, 259-263.

Sanz, P., Herrero, E., Valentin, E. \& Sentandreu, R. (1986). Una población de proteínas de la pared de las levaduras es secretada independientemente de la ruta definida por los mutantes sec. Abstracts of III Reunión Conjunta de Micologia, p. 94. Jarandilla de la Vera, Cáceres, Spain: Sociedad Española de Microbiología.

ScheKman, R. (1985). Protein localization and membrane traffic in yeast. Annual Review of Cell Biology 1, 115-143.

Tomasz, A. \& Westerphal, M. (1971). Abnormal autolytic enzyme in a pneumococcus with altered teichoic acid composition. Proceedings of the National Academy of Sciences of the United States of America 68, 2627-2630. 